\author{
О. К. Леонович, С. А. Дупанов
}

Белорусский государственный технологический университет

\title{
ИССЛЕДОВАНИЕ ХИМИЧЕСКИХ И СТРУКТУРНЫХ СВОЙСТВ НАТУРАЛЬНОГО МОРЕНОГО ДУБА МЕТОДОМ СКАНИРУЮЩЕЙ МИКРОСКОПИИ
}

В статье проведен химический и структурный анализ образцов мореного дуба - ценнейшего природного ресурса различных периодов залегания в поймах реки СОЖ. В результате исследований установлено увеличение содержания химических соединений железа и кальция и уменьшение содержания углерода в структуре натурального мореного дуба в зависимости от периодов залегания: 1000, 1500, 2000, 3000, 4000, 5000 лет. Абсолютный возраст образцов определен радиоуглеродным методом путем счета $ß$ активности ${ }^{14} \mathrm{C}$ в бензоле, синтезируемом из углеродсодержащего образца Изменение минерального состава (натурального мореного дуба) зависит от минерального состава среды залегания и циклического движения уровня грунтовых вод со своим химическим составом. При залегании в грунте древесина мореного дуба также будет находиться под циклическим влиянием грунтовых вод со своим химическим составом. В зависимости от периода пребывания в той или иной среде минеральный состав древесины мореного дуба будет увеличивать процентное содержание соединений железа и кальция по сравнению с натуральной древесиной дуба. С увеличением срока залегания происходят значительные структурные изменения микроскопического строения древесины. Крупные сосуды ранней зоны и мелкие сосуды поздней зоны имеют сплющенную форму. Сердцевинные лучи извилистые. Микроскопическая структура строения мореного дуба стала более искаженной и плотной. Стенки сосудов утолщены, а мелкие сосуды практически заполнены минеральными веществами, накопленными в течение тысячелетнего залегания в поймах рек и в результате химического взаимодействия дубильных веществ древесины дуба с солями железа, кальция и других соединений.

Ключевые слова: древесина, мореный дуб, микроскопия, структура, состав.

Для цитирования: Леонович О. К., Дупанов С. А. Исследование химических и структурных свойств натурального мореного дуба методом сканирующей микроскопии // Труды БГТУ. Сер. 1, Лесное хоз-во, природопользование и перераб. возобновляемых ресурсов. 2021. № 1 (240). С. 150-155.

O. K. Leonovich, S. A. Dupanov

Belarusian State Technological University

\section{RESEARCH OF THE CHEMICAL AND STRUCTURAL PROPERTIES OF NATURAL SEA OAK BY SCANNING MICROSCOPY}

The article provides a chemical and structural analysis of bog oak samples of a valuable natural resource of different periods in the floodplains of the coolant river. As a result of studies, an increase in the content of chemical compounds of iron and calcium and a decrease in the carbon content in the structure of natural bog oak were established depending on the occurrence periods: 1000, 1500, 2000, $3000,4000,5000$ years. The absolute age of the samples was determined by the radiocarbon method by counting the $\beta$ activity of ${ }^{14} \mathrm{C}$ in benzene synthesized from a carbon-containing sample. The change in the mineral composition (natural bog oak) depends on the mineral composition of the occurrence medium and the cyclic movement of the groundwater level with its chemical composition. When lying in the ground, bog oak wood will also be in the cyclic influence of groundwater with its chemical composition. Depending on the period of stay in a particular environment, the mineral composition of bog oak will increase the percentage of iron and calcium compounds compared to natural oak wood. With an increase in the period of occurrence, significant structural changes in the microscopic structure of wood occur. Large vessels of the early zone and small vessels of the late zone have a flattened shape. The medullary rays are sinuous. The microscopic structure of the bog oak structure has become more distorted and dense. The walls of the vessels were thickened, and the small vessels were practically filled with minerals accumulated during a thousand-year occurrence in the floodplains of rivers and the chemical interaction of the tannins of oak wood with salts of iron, calcium and other compounds.

Key words: wood, stained oak, microscopy, structure, composition.

For citation: Leonovich O. K., Dupanov S. A. Research of the chemical and structural properties of natural sea oak using scanning microscopy. Proceeding of BSTU, issue 1, Foresty. Nature Management. Processing of Resources, 2021, no. 1 (240), pp. 150-155 (In Russian) 
Введение. Мореный дуб - ценный невосполнимый природный ресурс, отличающийся от древесины обычного дуба структурой, химическими и физико-механическими свойствами. Новые характеристики мореный дуб приобретает за тысячелетия нахождения во влажной среде без доступа кислорода. В зависимости от места залегания мореного дуба и продолжительности цикла нахождения в новой среде содержащиеся в нем дубильные вещества, реагируя с солями железа, придают вариативный окрас. Возраст мореного дуба определяется анализом радиоуглеродного датирования.

В ряде работ приводятся разрозненные сведения о технических свойствах древесины мореного дуба и его ценности, а также и преимуществах при правильно организованном промышленном использовании [1-17].

В процессе переработки натурального мореного дуба возникают сложности в определении его возраста, качественных характеристик по визуальным оценкам, а также методами бесконтактного определения химических, физических и возрастных характеристик, позволяющих идентифицировать и подтвердить качественные характеристики наиболее простыми, доступными методами. Определение качественных характеристик этого ценнейшего природного ресурса расширит область его использования.

Для организации изготовления изделий высокого ценового диапазона из массива натурального мореного дуба соответствующего качества, ориентированного на экспорт, а также производства высококачественных эксклюзивных мебельных и отделочных материалов, востребованных в государственно-представительных структурах, в значимых общественных проектах, выставочных залах, театрах, где целесообразность использования ценного природного ресурса - натурального мореного дуба неоспорима, и для достоверного обоснованного использования мореного дуба необходимо:

- изучение поведения материала на всех этапах переработки в зависимости от качественных и возрастных параметров;

- создание технологического регламента на заготовку, сушку и дальнейшую переработку мореного дуба;

- исследование физико-химических свойств материала согласно качественно-возрастной группе;

- разработка регламента качественнооценочной характеристики натурального мореного дуба.

Известны методы для исследования ценных ископаемых останков животных и других живых существ: уран-ториевый (учитывается со- держание тория, который появляется в останках только после превращения живого существа в органические ископаемые), более чувствительный метод электронного парамагнитного резонанса (подсчитывается число сохранившихся неспаренных электронов) и метод термолюминесценции (нагревание образца вызывает испускание накопленной радиации, видимое как свечение), ЯМР-анализ. Данные методы исследования не нашли широкого применения для датирования ископаемого натурального мореного дуба.

Основная часть. Исследование натурального и мореного дуба в виде древесного материала и угольных остатков на микроуровне с анализом их химического состава проводили с использованием микроскопии.

Были взяты образцы натурального мореного дуба различной возрастной группы: 1000, 1500, $2000,3000,4000,5000$ лет согласно актам радиоуглеродного датирования, подтвержденным Национальной академией наук Беларуси.

Для определения структурных и химических свойств натурального и мореного дуба разных периодов залегания был использован сканирующий электронный микроскоп JSM-5610 LV с системой химического анализа EDX JED-2201JEO, который позволяет проводить одновременно автоматический качественный и количественный химический анализ. На рис. 1 показан прибор для сканирующей электронной микроскопии с энергодисперсионным химическим анализом.

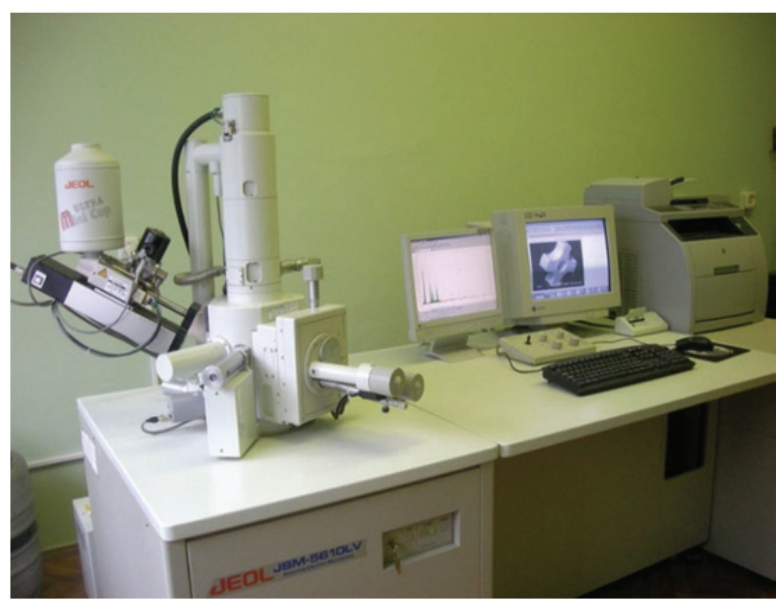

Рис. 1. Сканирующий электронный микроскоп JSM-5610 LV JEOL (Япония)

Микросъемку поверхности заранее подготовленных образцов древесины натурального мореного дуба размером $10 \times 10 \times 10$ мм помещали в герметичную камеру рабочей части микроскопа, после чего из пространства автоматически откачивали воздух для увеличения точности измерений и качества снимков. 
С помощью графического интерфейса, исполненного под MSWindows, и ситемы автоматического управления подвижным столом микроскопа (по двум координатам), а также приближения-удаления объектива возможно получение 8-битных (оттенки серого) снимков поверхности пробы при различном приближении. Снимки древесины получали с приближением в 100 и до 500 раз.

Система химического анализа EDX JED-2201JEO позволяет одновременно проводить автоматический качественный и количественный химический анализ до 99 участков изображения исследуемого образца, также получать карты и профили распределения элементов.

Разрешающая способность микроскопа JSM-5610 LV составляет 3,0-4,5 нм, кратность увеличения - 18-300 000. Анализируемые элементы системы химического микроанализа от В (бор) до U (уран), диапазон определяемых концентраций - 0,1-100\%.

В результате проведения спектроскопии натурального мореного дуба широкой возрастной группы были получены следующие данные (таблица).

Результат спектроскопии натурального мореного дуба широкой возрастной группы (анализ содержания элементов периодической таблицы в зависимости от возраста натурального мореного дуба)

\begin{tabular}{|c|c|c|c|}
\hline \multicolumn{4}{|c|}{ Возраст 1000 лет } \\
\hline \multicolumn{2}{|c|}{ Радиальный срез } & \multicolumn{2}{|c|}{ Торцевой срез } \\
\hline Элемент & Macca, $\%$ & Элемент & Macca, \% \\
\hline $\mathrm{C}$ & 89,66 & $\mathrm{C}$ & 89.66 \\
\hline $\mathrm{O}$ & 2,44 & $\mathrm{O}$ & 2,44 \\
\hline $\mathrm{Si}$ & 0,35 & $\mathrm{Si}$ & 0.35 \\
\hline $\mathrm{K}$ & 4,69 & $\mathrm{~K}$ & 4,69 \\
\hline $\mathrm{Ca}$ & 2,29 & $\mathrm{Ca}$ & 2,29 \\
\hline $\mathrm{Fe}$ & 0,58 & $\mathrm{Fe}$ & 0.58 \\
\hline Total & 100.00 & Total & 100.00 \\
\hline \multicolumn{4}{|c|}{ Возраст 1500 лет } \\
\hline \multicolumn{2}{|c|}{ Радиальный срез } & \multicolumn{2}{|c|}{ Торцевой срез } \\
\hline Элемент & Macca, $\%$ & Элемент & Macca, \% \\
\hline $\mathrm{C}$ & 90,53 & $\mathrm{C}$ & 90,64 \\
\hline $\mathrm{O}$ & 2,68 & $\mathrm{O}$ & 2,68 \\
\hline $\mathrm{Si}$ & 0,39 & $\mathrm{Si}$ & 0.53 \\
\hline $\mathrm{K}$ & 0,45 & $\mathrm{~K}$ & 1,16 \\
\hline $\mathrm{Ca}$ & 3,88 & $\mathrm{Ca}$ & 3,69 \\
\hline $\mathrm{Fe}$ & 2,07 & $\mathrm{Fe}$ & 1,3 \\
\hline Total & 100.00 & Total & 100.00 \\
\hline \multicolumn{4}{|c|}{ Возраст 2000 лет } \\
\hline \multicolumn{2}{|c|}{ Радиальный срез } & \multicolumn{2}{|c|}{ Торцевой срез } \\
\hline Элемент & Macca, \% & Элемент & Macca, \% \\
\hline $\mathrm{C}$ & 77,67 & $\mathrm{C}$ & 83,79 \\
\hline $\mathrm{O}$ & 5,76 & $\mathrm{O}$ & 4,15 \\
\hline $\mathrm{Si}$ & 0,88 & $\mathrm{Si}$ & 0.42 \\
\hline
\end{tabular}

Окончание таблицы

\begin{tabular}{|l|c|l|c|}
\hline \multicolumn{4}{|c|}{ Возраст 2000 лет } \\
\hline \multicolumn{2}{|c|}{ Радиальный срез } & \multicolumn{2}{c|}{ Торцевой срез } \\
\hline Элемент & Масса, \% & Элемент & Масса, \% \\
\hline $\mathrm{K}$ & 4,82 & $\mathrm{~K}$ & 1,85 \\
\hline $\mathrm{Ca}$ & 5,83 & $\mathrm{Ca}$ & 4,41 \\
\hline $\mathrm{Fe}$ & 5,04 & $\mathrm{Fe}$ & 5,38 \\
\hline Total & 100.00 & Total & 100.00 \\
\hline \multicolumn{4}{|c|}{ Возраст 3000 лет } \\
\hline
\end{tabular}

\begin{tabular}{c|c}
\hline Радиальный срез & Торцевой срез \\
\hline
\end{tabular}

\begin{tabular}{|l|c|l|c|}
\hline Элемент & Масса, $\%$ & Элемент & Масса, \% \\
\hline $\mathrm{C}$ & 73,33 & $\mathrm{C}$ & 72,32 \\
\hline $\mathrm{O}$ & 6,69 & $\mathrm{O}$ & 7,01 \\
\hline $\mathrm{Si}$ & 0,31 & $\mathrm{Si}$ & 0.51 \\
\hline $\mathrm{K}$ & 1,18 & $\mathrm{~K}$ & 1,05 \\
\hline $\mathrm{Ca}$ & 7,03 & $\mathrm{Ca}$ & 6,51 \\
\hline $\mathrm{Fe}$ & 11,46 & $\mathrm{Fe}$ & 12,6 \\
\hline Total & 100.00 & Total & 100.00 \\
\hline
\end{tabular}

\begin{tabular}{|c|c|c|c|}
\hline \multicolumn{4}{|c|}{ Возраст 4000 лет } \\
\hline \multicolumn{2}{|c|}{ Радиальный срез } & \multicolumn{2}{|c|}{ Торцевой срез } \\
\hline Элемент & Macca, \% & Элемент & Macca, $\%$ \\
\hline $\mathrm{C}$ & 69,50 & $\mathrm{C}$ & 74,87 \\
\hline $\mathrm{O}$ & 7,19 & $\mathrm{O}$ & 6,20 \\
\hline $\mathrm{Si}$ & 0,65 & $\mathrm{Si}$ & 0.63 \\
\hline $\mathrm{K}$ & 3,93 & $\mathrm{~K}$ & 0,67 \\
\hline $\mathrm{Ca}$ & 2,45 & $\mathrm{Ca}$ & 2,60 \\
\hline $\mathrm{Fe}$ & 16,28 & $\mathrm{Fe}$ & 15,04 \\
\hline Total & 100.00 & Total & 100.00 \\
\hline \multicolumn{4}{|c|}{ Возраст 5000 лет } \\
\hline \multicolumn{2}{|c|}{ Радиальный срез } & \multicolumn{2}{|c|}{ Торцевой срез } \\
\hline Элемент & Macca, \% & Элемент & Macca, \% \\
\hline $\mathrm{C}$ & 70,49 & $\mathrm{C}$ & 73,77 \\
\hline $\mathrm{O}$ & 7,49 & $\mathrm{O}$ & 6,59 \\
\hline$\underline{\mathrm{Si}}$ & 0,45 & $\mathrm{Si}$ & 0.33 \\
\hline $\mathrm{K}$ & 1,40 & $\mathrm{~K}$ & 0,40 \\
\hline $\mathrm{Ca}$ & 8,08 & $\mathrm{Ca}$ & 6,30 \\
\hline $\mathrm{Fe}$ & 12,09 & $\mathrm{Fe}$ & 12,62 \\
\hline Total & 100.00 & Total & 100.00 \\
\hline
\end{tabular}

Древесина состоит из органических веществ, в состав которых входят углерод, водород, кислород и немного азота. Элементарный химический состав древесины разных пород практически одинаков. В среднем абсолютно сухая древесина независимо от породы содержит 49,5\% углерода, 44,2\% кислорода (с азотом) и $6,3 \%$ водорода. Элементарный химический состав древесины ствола и ветвей мало различается. Условия произрастания также практически не отражаются на содержании основных элементов. Кроме органических веществ, в древесине есть минеральные соединения, дающие при сгорании золу, количество которой колеблется в пределах $0,2-1,7 \%$;

Органический состав натурального мореного дуба значительно отличается от любого 
другого вида дерева. Содержание углерода 70-90\%, кислорода $-2-8 \%$.

Минеральный состав также очень богат: содержание железа - до $16 \%$, кальция - до $8 \%$ а также выявлен ряд других элементов в большом количестве, отраженных в таблице.

Также наблюдается закономерность увеличения процентного содержания минеральной составляющей мореного дуба от времени пребывания в бескислородной среде.

На диаграмме (рис. 2) визуально отображена выдержка данных из таблицы и приведен снимок сосудистой системы мореного дуба возрастом 4000 лет (рис. 3).

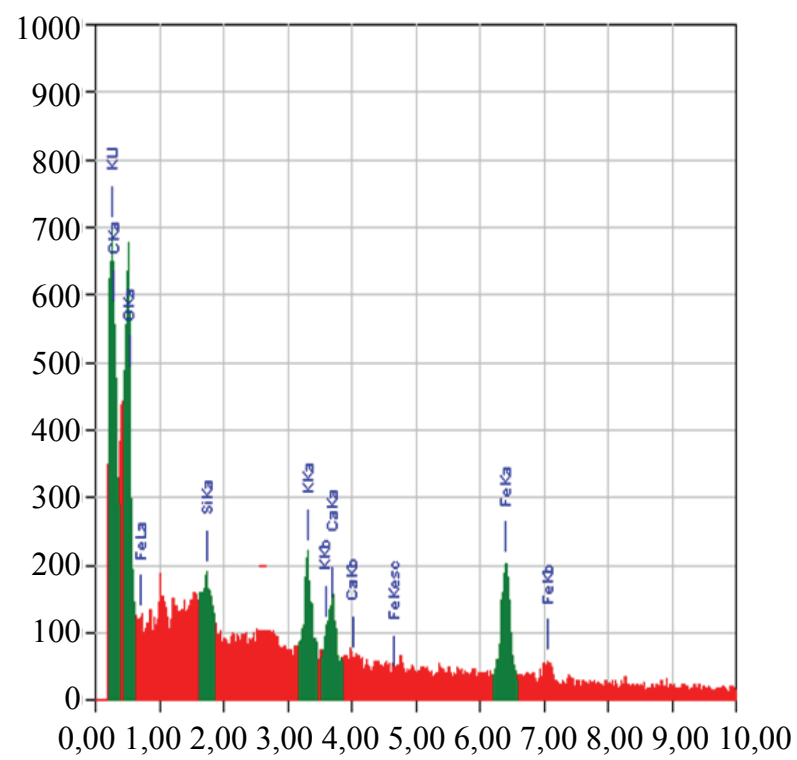

Рис. 2. Диаграмма, полученная в результате спектроскопии образца возрастом (4000 лет)

При испытании образцов мореного дуба с установленными периодами возраста от 1000 до 5000 лет определено, что содержание углерода уменьшилось с 89,66 до 70,49\%, кислорода увеличилось с 2,44 до $7,49 \%$, калия уменьшилось с 4,69 до $1,40 \%$, кальция увеличилось с 2.29 до $8,08 \%$.

Особенно заметно изменение процентного содержание железа (см. радиальный срез в таблице). Так, при возрасте 1000 лет его содержание составляет 0,58\%, 1500 лет - 2,07\%, 2000 лет $5,04 \%, 3000$ лет - 11,46\%, 4000 лет - 16,28\%.

Изменение минерального состава мореного дуба зависит от минерального состава среды залегания этого ценного природного ресурса. В процессе придонного залегания на мореный дуб действует постоянный поток воды, имеющий свой химический состав.

В зависимости от периода пребывания в той или иной среде минеральный состав древесины мореного дуба будет увеличивать свое процентное соотношение к органическому (исходному) составу. Структура мореного дуба становится извилистой и более плотной.

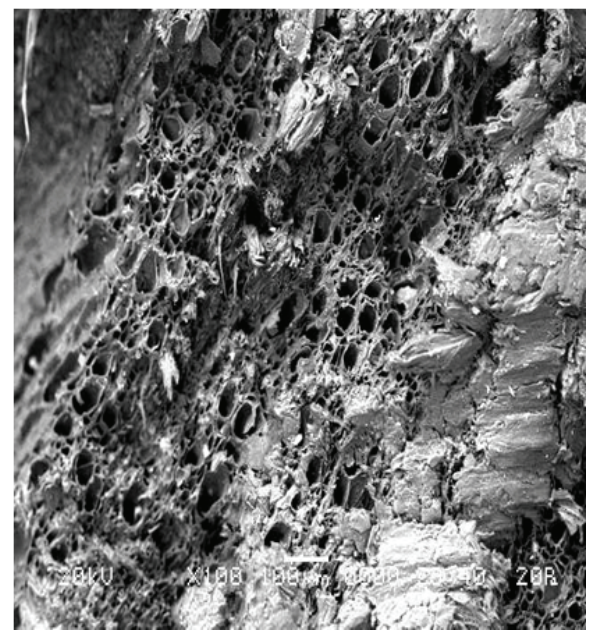

Рис. 3. Снимок сосудистой системы натурального мореного дуба в приближении $\times 100$ (4000 лет)

Заключение. Исследование химического состава такого природного ресурса, как мореный дуб, позволит решить ряд проблем, связанных с его переработкой.

Установлена закономерность изменения процентного содержания химических элементов в структуре мореного дуба в зависимости от возраста. Структура строения мореного дуба приобрела извилистые уплотненные формы. Предложено использовать анализ спектроскопии как альтернативный радиоуглеродному анализу.

\section{Список литературы}

1. Петруша А. К. Технические свойства древесины мореного дуба и его промышленное использование // Сборник научных трудов БЛТИ им. С. М. Кирова. Минск, 1948. Вып. VII. С. 11-37.

2. Дупанов А. А. Мореный дуб // ЛесПромИнформ. 2005. № 4 (26). С. 6-7.

3. Дупанов А. А. Основные проблемы добычи и переработки мореного дуба // ЛесПромИнформ. 2005. № 7 (29). С. 9.

4. Дупанов А. А. Изделия из мореного дуба // ЛесПромИнформ. 2006. № 2 (33). С. 7.

5. Дупанов А. А. Сложности деревообработки мореного дуба // Дерево.Ru. 2019. 1 (36). C. $10-12$.

6. Леонович О. К. Стратегия инновационного развития лесопромышленного комплекса // Материалы 84-й науч.-техн. конф., посвященной 90-летнему юбилею БГТУ и Дню белорусской науки 
(с международным участием), Минск, 3-14 февраля 2020 г. Минск: БГТУ, 2020. C. 13-15 URL: https://www.belstu.by/science/obschaya-informaciya/conferencesandexhibitions/2020-god/84-ya-nauchnotehnicheskaya-konferenciya-professorsko-prepodavatelskogo-sostava-nauchnyh-sotrudniko.html (дата обращения: 22.12.20).

7. Леонович О. К., Дупанов С. А. Перспективные направления переработки натурального мореного дуба // Материалы 84-й науч.-техн. конф., посвященной 90-летнему юбилею БГТУ и Дню белорусской науки (с международным участием), Минск, 3-14 февраля 2020 г. Минск: БГТУ, 2020. C. 17-20. URL: https://www.belstu.by/science/obschaya-informaciya/conferencesandexhibitions/2020god/84-ya-nauchno-tehnicheskaya-konferenciya-professorsko-prepodavatelskogo-sostava-nauchnyh-sotrud niko.html (дата обращения: 12.09.2019).

8. Сканирующая электронная микроскопия как метод изучения микроскопических объектов электролитического происхождения / И. С. Ясников [и др.] // Фундаментальные исследования. 2013. № 1-3. С. 758-764. URL: http://www.fundamental-research.ru/ru/article/view?id=31024 (дата обращения: 12.09.2019).

9. Пауль Э. Э., Звягинцев В. Б., Древесиноведение с основами лесного товароведения. Минск: БГТУ, 2015. 315 с.

10. Фенгел Д., Венегер Г. Древесина (химия, ультраструктура, реакция). М.: Лесная пром-сть, 1988. $512 \mathrm{c}$.

11. Антоник А. Ю., Леонович О. К. Структурные изменения древесины сосны при термомодифицировании // Материалы 81-й науч-тех. конф. профессорско-преподавательского состава, науч. сотрудников и аспирантов (с международным участием). Минск, 1-12 февраля 2017. Минск, 2017. URL: https://www.belstu.by/science/obschaya-informaciya/conferencesandexhibitions/2017-god/81-ya-nauchno-tehnicheskaya-konferenciya.html (дата обращения: 12.09.2019).

12. Антоник А. Ю. Эколого-химические свойства термомодифицированной древесины сосны // 68-я науч.-техн. конф. учащихся, студентов и магистрантов: сб. науч. работ, Минск, 17-22 апреля 2017. Минск, 2017. URL: https://www.belstu.by/science/obschaya-informaciya/conferencesand exhibitions/2017-god/68-ya-nauchno-tehnicheskaya-konferenciya-uchaschihsya-studentov-i-magistrantov.html (дата обращения: 12.09.2019).

13. Аксенов П. А., Коровин В. В. Химический состав древесины дуба, используемой для производства коньяка и бренди // Лесной вестник. 2009. № 1. С. 5-16. URL: https://cyberleninka.ru/article/n/himicheskiy-sostav-drevesiny-duba-ispolzuemoy-dlya-proizvodstva-konyaka-i-brendi-1(дата обращения: 12.09.2019).

14. Азаров В. И., Буров А. В., Оболенская А. В. Химия древесины и синтетических полимеров. СПб.: СПбЛТА, 1999. $628 \mathrm{c.}$

15. Альтшулер С. А., Козырев Б. М. Электронный парамагнитный резонанс соединений элементов промежуточных групп. М.: Наука, 1972. 672 с.

16. Уран-ториевое датирование высоких морских террас архипелага Шпицберген / Ф. Е. Максимов [и др.] // Вестн. С.-Петерб. ун-та. Сер. 7, Геология. География. 2016. Вып. 2. С. 54-64. DOI: $10.21638 / 11701 / \mathrm{spbu07.2016.205.}$

17. Франк М., Штольц В. Дозиметрия ионизирующего излучения. М.: Атомиздат, 1973. 246 с.

\section{References}

1. Petrusha A. K. Technical properties of wood stained oak and its industrial use. Sbornik nauchnykh trudov BLTI im. S. M. Kirova [Collection of scientific works of the S. M. Kirov BSTI], issue VII. Minsk, 1948, pp. 11-37 (In Russian).

2. Dupanov A. A. Bog oak. LesPromInform [LesPromInform], 2005, no. 4 (26), p. 7 (In Russian).

3. Dupanov A. A. The main problems of extraction and processing of bog oak. LesPromInform [LesPromInform], 2005, no. 7 (29), p. 9 (In Russian).

4. Dupanov A. A. Products from bog oak [LesPromInform], 2006, no. 2 (33), p. 7 (In Russian).

5. Dupanov A. A. Difficulties of woodworking bog oak. Derevo.RU [Derevo.RU], 2019, 1 (36), pp. 10-12 (In Russian).

6. Leonovich O. K. Strategy for innovative development of the timber industry complex. Materialy 84-y nauch.-tekhn. konf., posvyashchennoy 90-letnemu yubileyu BGTU i Dnyu belorusskoy nauki, Minsk, 3-14 fevralya 2020 [Materials 84th scientific-technical conference dedicated to the 90th anniversary of BSTU and the Day of Belarusian Science (with international participation), Minsk, February 3-14, 2020]. Minsk, BGTU Publ., 2020, pp. 13-16. Available at: https://www.belstu.by/science/obs chaya-informaciya/conferencesandexhibitions/2020-god/84-ya-nauchno-tehnicheskaya-konferenciya-professorsko-prepodavatelskogo-sostava-nauchnyh-sotrudniko.html (accessed 12.09.2019). 
7. Leonovich O. K. Dupanov S. A. Promising directions of processing of nature bog oak. Materialy 84-y nauch.-tekhn. konf., posvyashchennoy 90-letnemu yubileyu BGTU i Dnyu belorusskoy nauki, Minsk, 3-14 fevralya 2020 [Materials 84th scientific-technical. conference dedicated to the 90th anniversary of BSTU and the Day of Belarusian Science (with international participation), Minsk, February 3-14, 2020]. Minsk:, BGTU Publ., 2020, pp. 17-20. Available at: https://www.belstu.by/science/obschaya-informaciya/conferencesandexhibitions/2020-god/84-ya-nauchno-tehnicheskaya-konferenciya-professorsko-prepodavatelskogo-sostava-nauchnyh-sotrudniko.html (accessed 12.09.2019).

8. Yasnikov I. S., Nagornov Yu. S., Gorbachev I. V., Mikeyev R. R., Sadovnikov P. S, Shubchinskaya N. Yu., Aminarov A. V. Scanning electron microscopy as a method for studying microscopic objects of electrolytic origin. Fundanental'nyye issledovaniya [Fundamental research], 2013, no. 1-3, pp. 758-764 (In Russian). Available at: http://www.fundamental-research.ru/ ru/article/view?id=31024 (accessed 12.09.2019).

9. Paul E. E., Zvyagintsev V. B. Drevesinovedeniye s osnovami lesnogo tovovedeniya [Wood science with the basics of forest commodity science]. Minsk, BGTU Publ., 2015. 315 p.

10. Fengel D., Veneger G. Drevesina (khimiya, ul'trastruktura, reaktsiya) [Wood (chemistry, ultrastructure, reaction)]. Moscow, Lesnaya prom-st' Publ., 1988. 512 p.

11. Antonik A. Yu., Leonovich O. K. Structural changes in pine wood during thermal modification. $S b$. nauch. rabot 81-y nauch.-tekhn. konf. professorsko-prepodavatel'skogo sostava, nauch. sotrudnikov $i$ aspirantov (s mezhdunarodnym uchastiyem). Minsk, 1-12 fevralya, $2017 \mathrm{~g}$. [Collection of scientific articles, 81 st scientific and technical conference of faculty, researchers and graduate students (with international participation). Minsk, February 1-12, 2017]. Minsk, BGTU Publ., 2017. Available at: https://www.belstu.by/science/obschaya-informaciya/conferencesandexhibitions/2017-god/81-ya-nauchno-tehnicheskaya-konferenciya.html (accessed 12.09.2019).

12. Antonik A. Yu. Ecological and chemical properties of thermomodified pine wood. Sb. nauch. rabot 68-y nauch.-tekhn. konf. uchashchikhsya, studentov i magistrantov, Minsk, 17-22 aprelya $2017 \mathrm{~g}$. [Collection of scientific articles 68th scientific and technical conference of pupils, students and undergraduates. Minsk, 17-22 April 2017]. Minsk, BGTU, 2017. Available at: https://www.belstu.by/science/obschayainformaciya/conferencesandexhibitions/2017-god/68-ya-nauchno-tehnicheskaya-konferenciya-uchaschihsyastudentov-i-magistrantov.html (accessed: 12.09.2019).

13. Aksenov P. A., Korovin V. V. Chemical composition of oak wood used for the production of cognac and brandy. Lesnoy vestnik [Forest Bulletin], 2009, no 1, pp. 5-16 (In Russian). Available at: https://cyberleninka.ru/article/n/himicheskiy-sostav-drevesiny-duba-ispolzuemoy-dlya-proizvodstva-konyaka-i-brendi-1 (accessed 12.09.2019).

14. Azarov V. I., Burov A. V., Obolenskaya A. V. Khimiya drevesiny i sinteticheskikh polimerov [Chemistry of wood and synthetic polymers]. St. Petersburg, SPbLTA Publ., 1999. 628 p.

15. Al'tshuler S. A, Kozyrev B. M Elektronnyy paramagnitnyy rezonans soyedineniy elementov promezhutochnykh grupp [Electron paramagnetic resonance of compounds of elements of intermediate groups]. Moscow, Nauka Publ., 1972. 672 p.

16. Maksimov F. E., Sharin V. V., Kuznetsov V. Yu., Okunev A. S., Grigoriev V. A., Petrov A. Yu. Uraniumthorium dating of high sea terraces of the Spitsbergen archipelago. Vestnik Sankt-Peterburgskogo universiteta [Bulletin of the St. Petersburg University], series 7, Geology. Geography, 2016, issue 2, pp. 54-64 (In Russian).

17. Frank M., Stolz V. Dozimetriya ioniziruyushchego izlucheniya [Dosimetry of ionizing radiation]. Moscow, Atomizdat Publ., 1973. 246 p.

\section{Информация об авторах}

Леонович Олег Константинович - кандидат технических наук, доцент кафедры технологии деревообрабатывающих производств. Белорусский государственный технологический университет (220006, г. Минск, ул. Свердлова, 13a, Республика Беларусь). E-mail: OKL2001@mail.ru

Дупанов Сергей Александрович - магистрант кафедры технологии деревообрабатывающих производств. Белорусский государственный технологический университет (220006, г. Минск, ул. Свердлова, 13a, Республика Беларусь). E-mail: serge.zubr@yandex.by

\section{Information about the authors}

Leonovich Oleg Konstantinovich - PhD (Engineering), Assistant Professor, the Department of Woodworking Technology. State Technological University (13a, Sverdlova str., 220006, Minsk, Republic of Belarus).E-mail: OKL2001@mail.ru

Dupanov Sergey Aleksandrovich - Master's degree student, the Department of Woodworking Technology. Belarusian State Technological University (13a, Sverdlova str., 220006, Minsk, Republic of Belarus). E-mail: serge.zubr@yandex.by 